\title{
Synthesis Study of Nucleus-cell Style High-property
}

\section{Water-absorbent Polymer}

\author{
Cuirong Zhang, Shucai Mao \& Zhenyu Jia \\ Institute of Green Chemical Engineering \\ Zhongkai Agriculture Engineering College \\ Guangzhou 510230, China
}

\begin{abstract}
In this paper, MBA was used as crosslinker, $\mathrm{SiO}_{2}$ and carboxymethyl cellulose as the nucleus-maker, nucleus-cell style SAP was synthesized by AA-AM-AMPS three-member copolymerization. The multiple of water-absorbent by SAP could reach 1150 times by the optimization of the technological conditions. Nucleus-cell style SAP has a good command of fluidity and wet-resistance, it can keep its fluidity $15 \mathrm{hrs}$ after exposure under the air with the humidity of $84 \%$. The best proportion of AA, AM, AMPS is 13:3:4, and the best content of $\mathrm{SiO}_{2}$ is $0.8 \%$.
\end{abstract}

Keywords: Water-absorbent polymer, Nucleus-cell style, Step-crosslinking

Water-absorbent polymer, a kind of function material, can absorb water weigh as hundreds times even thousands times as themself. SAP has been applied in industry, agriculture, medical and treatment, gardening, etc. SAP developed very fast in nearly years. Different kinds of SAP have been prepared, such as synthesized polymers, amylum species, cellulose species, etc. SAPs from modified amylum or cellulose can be biodegraded but are easy to corrupt and conglomerate. Their heat resistance, water-keeping performance and gel intensity are poor. Also preparation process is complicated. Two kinds of technology were used to make SAP by acryl acid. One was solution polymerization (disc polymerization) process; the other was reversal-phase suspension polymerization process. At present, SAP made by solution polymerization was of poor moisture proof and was prone to absorb moisture at ambient temperature and at usual relative humidity in practically application. This make it inconvenient to apply, store, transport, packing, produce and machining. Even make it incapable to use. A kind of core-shell high-quality SAP had been synthesized by reverse-phase suspending polymerization in this work. Monomers ratio and other process conditions were studied. FTIR and High power microscope were used to observe core-shell forming and association.

\section{Experimental}

\subsection{Materials}

Acryl acid(AA), Acrylamide(AM), 2-acrylamide-2-methyl-propane sulfoacid sodium (AMPS), N,N-methylene-bia-acrylamide(MBA), ammonium persulfate(APS), hydrosulfite of sodium, sodium hydroxide, cyclohexane, surfactant(SP-85, OP-7), carboxymethyl cellulose. All were chemically pure. Silicon dioxide(superfine powder-700 mesh size) was supplied by Chengdu chemical plant.

\subsection{Procedure}

First, AA was neutralized by $\mathrm{NaOH}$ solution and neutralization degree reached 80-85\%; second, some AM, AMPS, cross-linker MBA as well as initiator solution were added in and were stirred to get A solution(water phase). Composite surfactant (SP-85:OP-7=1:1) were added in cyclohexane phase and were stirred to disperse enough, so B solution was gotten. B solution was placed into a four-neck flask and was stirred, and then $95 \%$ A was added in slowly. They reacted one hour at certain temperature. Then residual A solution as well as cross-linker, cellulose, $\mathrm{SiO}_{2}$ was added in the flask too. The reaction went on for another three hours. After filtration and separation quickly, product was washed by methanol and was dried to get granular polymer.

\section{3 structure and properties test}

(1) Test of water- absorbent speed (whirlpool method): pour water in beakers; put beakers on magnetic stirring apparatus; turn on it and muddler make water whirlpool. Pour $0.5 \mathrm{~g}$ SAP into water and record time by stopwatch until whirlpool disappears. Find out the relationship between water-absorbent and the time.

(2)multiple test of absorbing and solution (net method): put $1 \mathrm{~g}$ SAP in beakers. Put $0.9 \% \mathrm{NaCl}$ solution, $0.9 \% \mathrm{CaCl}_{2}$ 
solution, distilled water, tap water, and soil lixivium etc into beaker respectively. When SAP absorbs liquid balance, excrescent liquid is filtered by 100 -mesh net. Weight and work out the absorbing \& solution multiple.

$\mathrm{Q}=(\mathrm{W} 1-\mathrm{W} 2) / \mathrm{M}$

In formula: Q- absorbing \& solution multiple; W1-SAP weigh after absorbing(g); W2- net weigh(g); M-SAP weigh(g).

(3) fluidity test(angle of repose): samples in filler flow to horizontal desktop spontaneously. Test samples' angle of repose. Fluidity is poor if the angle is greater than $45^{\circ}$, and fluidity is good if it is smaller than $45^{\circ}$.

(4) test of humidity resistance: judge samples' humidity resistance by test their hygroscopic capacity at different time and moisture condition.

(5) observe samples' morphologies by high-quality microscope.

(6) FTIR : FTIR was got by NiColet-170SX instrument after samples were dealt with KBr by pressed disc method.

\section{2. results and discussion}

\section{1 monomers affection on SAP'S properties}

Figure 1 presented that water-absorbent multiple decreased and salt water-absorbent multiple increased, while degree of cross linking, degree of neutralization and reaction temperature kept invariable with AM monomer's increasing. AM contained amido which belonged to non-ion hydrophilic group and was of strong property of salt-resistance. With amido increasing, -N-H-O-hydrogen bonds tended to form between polymer chains within network structure. Cohesive energy increased. Intensity increases and water-absorbent multiple decreased. With AMPS monomer's ratio increasing, salt-absorbent ratio and water-absorbent ratio increased accordingly. $-\mathrm{SO}_{3} \mathrm{H}$ was strong hydrophilic ionic group. With its ratio increasing, ionicity of SAP network increased too. The osmotic pressures both in network and out network increased, and then water-absorbent increased accordingly. Ion in solvent had important influence on water-absorbent performance of SAP. The influence of $\mathrm{Ca}^{2+}$ was stronger than $\mathrm{Na}^{+}$at the same concentration. $\mathrm{Ca}^{2+}$ entered into SAP net and was easy to form complex compound with carboxylic radical, which reduced repulsion between anions, so increased elastic behaviour of gelatum made water-absorbent multiple of SAP decrease. In thermodynamics opinion, Flory quantitatively stated how water-absorbent performance of SAP related to ion concentration in solvent, charge density of polymer, degree of cross linking and the appetency of groups in net to water. With degree of cross linking increasing, water-absorbent multiple decreased; with ion concentration in solvent increasing, water-absorbent multiple decreased too. In order to improve water-absorbent multiple and water-absorbent speed, strong hydrophilic groups including hydrophilic non-ionic groups could be introduced in polymer. Experimental results accorded with that theory basically. Of its performances, water-absorbing multiple, water-absorbing speed, gel intensity and salt resistance were mostly pursued by people and also were considered in actual application. According to molecule designing opinion, copolymerization of two members or three members even several members was valid way to improve SAP performances. When any two components of AA, AM and AMPS copolymerized, the most water-absorbing multiple was 916 times. While three components copolymerized, it increased to 1150 times.

Figure1 showed that water-absorbing speed rate curve of core-shell SAP was "S" shape. Shell made speed rate slower at the beginning. When shell split, water entered in quickly. Proper thickness of shell didn't influence water-absorbing multiple and speed rate. The shell could protect SAP against moisture. During the process of water-absorbing, SAP surface carried through hydration ionization firstly. More was hydration ionization degree, more would water-solubility increase. sol came into being and ion film did simultaneously, which held back water's penetration and influenced water-absorbing speed rate, so ionic group content could't be more, otherwise water-absorbing multiple would decrease. Amido was of stronger hydrophilicity and formed hydrogen bond with water molecule, which increased the hydrophilicity and improved water-absorbing speed rate greatly. Core-shell SAP could achieve water-absorbing saturation in 10 minutes.

Figure 2 showed that moisture absorption speed of core-shell SAP was slower at the incipient stage in humidity atmosphere, which was mostly due to consumed time for polymer hydration and molecule chain stretching. As long as polymer chains stretched out, water-absorbing speed would accelerate. In the case of the protection of shell, water-absorbing speed stayed slow because of poor affinity between water molecules and SAP. That was why core-shell resin owned better humidity resistance than general polymer. At $84 \%$ relative humidity, core-shell SAP could keep better fluidity after 15 hours at ambient temperature. Angles of repose were test to compare fluidity. That of Core-shell SAP was $36^{\circ}$ and that of non-core-shell production was $44^{0}$.

\section{2 temperature's influence on synthesis}

It could be seen form figure 3 that polymerization reaction kept stable and water-absorbing multiple was small at low temperature. When temperature rose to $70^{\circ} \mathrm{C}$, water-absorbing multiple of SAP achieved the highest peak. After that, water-absorbing multiple went down with temperature's continuous rising. Synthesising SAP belonged to free radical polymerization and exothermic reaction, while initiator's decomposing belonged to endothermic reaction. At low 
temperature initiator decomposed slowly. Their concentration and initiating efficiency were low, too. Cessation reaction and growth reaction was a pair of competitive reaction. The former activation energy (about $8.5-17 \mathrm{~kg} / \mathrm{mol}$ ) was lower than the latter's (about 17-34 kg/mol). Low temperature would make monomers' residual large and polymer molecular weigh small, which would have influence on water-absorbing multiple of SAP. Although suspending liquid could eliminate heat, AA polymerization was exothermic reaction, when temperature rose, initiator composed fast and initiating efficiency improved to make core temperature high. This made AA self-polymerize and cross-link, so that polymer clew couldn't stretch and water-absorbing multiple decreased. Figure 2 displayed that monomers' residual decreased with temperature rising at various temperature, which accorded with the above conclusion.

\section{3 degree of neutralization's influence}

Figure 4 indicated that water-absorbing multiple of SAP became larger with degree of neutralization increasing when other condition stayed unchanged. When degree of neutralization achieved $85 \%$ liquid-absorbing multiple reached the peak. Since the acidity of -SO3H group was stronger than that of $-\mathrm{COOH}$, when AMPS was added in the neutralized AA solution, AMPS would react with sodium acrylate and $-\mathrm{COOH}$ would be released, so in fact neutralization in general polymer was smaller than the data calculated on AA, which could be seemed as the concentration of AA increased. Reaction activity of AA was stronger than that of acrylate, AM and AMPS, so AA likely self-cross link, which made swelling capacity of polymer net decrease and water-absorbing multiple as well as water-solubility become small. When neutralization exceeded $85 \%$, would -COONa group increase. This reduced self-cross linking, but water-solubility increased, so water-absorbing multiple and speed would reduce too.

\subsection{Influence of addition of $\mathrm{SiO}_{2}$ on the effect on $\mathrm{SAP}$ core-forming}

Table 3 presented that humidity-resistance time of SAP increased with addition of $\mathrm{SiO}_{2}$ but the correlation was not direct proportion. When $\mathrm{SiO}_{2}$ quantity was little, particle surface of $\mathrm{SAP}$ couldn't be covered fully. When $\mathrm{SiO}_{2}$ quantity reached $0.8 \%$, the complete film formed and humility-resistance performance was promoted greatly. The addition quantity of $\mathrm{SiO}_{2}$ was not very large, so its influence on water-absorbing multiple and speed rate was little.

\subsection{FTIR analyses}

Figure 5 showed that Si-O stretching vibration was at $1108 \mathrm{~cm}^{-1}$ and flexural vibration was at $474 \mathrm{~cm}^{-1}$. Vibration peaks of $-\mathrm{OH}$ and Al-O occurred at $3412 \mathrm{~cm}^{-1}$ and $619 \mathrm{~cm}^{-1}$ respectively since the purity of $\mathrm{SiO}_{2}$

Figure 6 showed that $1570 \mathrm{~cm}^{-1}$ peak came from $\mathrm{C}=\mathrm{O}$ stretching vibration of amide group and carboxyl. Dissymmetric stretching vibration of $\mathrm{S}=\mathrm{O}$ occurred at $1330 \mathrm{~cm}^{-1}$ and its stretching vibration was at $1058 \mathrm{~cm}^{-1} .3412 \mathrm{~cm}^{-1}$ peak of $-\mathrm{OH}$ mean that $-\mathrm{SO} 3 \mathrm{H}$ existed. $1174 \mathrm{~cm}^{-1}$ and $513 \mathrm{~cm}^{-1}$ peaks represented stretching vibration and flexural vibration of Si-O respectively, which indicated that $\mathrm{SiO}_{2}$ was grafted at $\mathrm{SAP}$ surface and formed shell.

\subsection{SAP morphology observation by microscope}

Figure 7 showed that SAP made from reversal-phase suspending process were uniform spheres. Figure 8 presented the morphology after water-absorbing. Shell was obvious and it broke up after water-absorbing. Figure 9 showed the SAP morphology from solution polymerization processing. The powder products derived from massive products when they were cracked. Most particles were irregular.

\section{Conclusion}

a. When MBA was used as cross-linker and $\mathrm{SiO}_{2}$ was used as the nucleus-maker, SAP was synthesized by AA-AM-AMPS three-member copolymerization in reversal-phase suspending processing. The SAP possessed better water-absorbing capability. The water-absorbing multiple of SAP under the processing of optimizing the technological conditions could reach 1150 times. SAP possessed good fluidity and humidity-resistance. It could keep some fluidity after exposure to the air with $84 \%$ humidity for 15 hours.

b. No agglomeration and no adhesion occurred in the preparation processing. Hard operating process was overcome. The particles of SAP were uniform.

c. Under the preparation processing, temperature should be controlled from low to high. This could control the polymerization reaction effectively.

\section{References}

Cuiyingde,Guojianwei,Liaoliewen. Journal of Chemical Industry[J], 2001,52(7):601 605

Guojianwei, Cuiyingde,Kangzheng. Fine Chemicals[J], 2001, 6: 348 350

Jacek K, Dutkiewicz. Journal of Biomedical Material[J],2002,63(3):373 381

Longmingce,Wangpeng,Dengdong, Chemical communications[J], 2002, 10: 705 709

Qiuhaixia,Yujiumu,Lintong. Chemical communications[J], 2003, 9: 598 605 
Wangxiaodong,Wangyuan, Chemical engineer[J], 2001: 4:1 3

Zhouliming,Gaodechuan,Wangtiemin, Journal of Donghua University [J], 2001, 27(1): 10 12

Table 1. Influence of Monomer composition to absorbent resin (SAP) performance

\begin{tabular}{|c|c|c|c|c|c|}
\hline $\begin{array}{l}\text { Content of Monomer } \\
\text { components } \\
\text { W(AA+AM+AMPS } \%\end{array}$ & $\begin{array}{l}\text { Distilled } \\
\text { water } \\
\text { absorption } \\
\text { rate } \\
\mathrm{g} / \mathrm{g}\end{array}$ & $\begin{array}{l}\text { Salt water }(0.9 \%) \\
\text { absorption rate } \\
\mathrm{g} / \mathrm{g}\end{array}$ & $\begin{array}{l}\mathrm{CaCl}_{2} \\
(0.9 \%) \text { absorption } \\
\text { rate } \\
\mathrm{g} / \mathrm{g}\end{array}$ & $\begin{array}{l}\text { Tap water } \\
\text { absorption } \\
\text { rate } \\
\mathrm{g} / \mathrm{g}\end{array}$ & $\begin{array}{l}\text { Leaching } \\
\text { of soil } \\
\text { absorption } \\
\text { rate } \\
\mathrm{g} / \mathrm{g}\end{array}$ \\
\hline $100+0+0$ & 683 & 58 & 42 & 487 & 284 \\
\hline $90+3+5$ & 846 & 103 & 57 & 531 & 323 \\
\hline $85+6+10$ & 917 & 112 & 66 & 663 & 416 \\
\hline $80+10+10$ & 913 & 136 & 83 & 727 & 518 \\
\hline $75+10+15$ & 1020 & 148 & 96 & 786 & 542 \\
\hline $70+15+15$ & 1080 & 156 & 102 & 834 & 584 \\
\hline $65+15+20$ & 1150 & 230 & 113 & 897 & 672 \\
\hline $60+15+25$ & 830 & 211 & 106 & 710 & 524 \\
\hline $50+25+25$ & 610 & 88 & 62 & 580 & 390 \\
\hline $90+0+10$ & 720 & 89 & 58 & 716 & 462 \\
\hline $80+0+20$ & 857 & 109 & 88 & 792 & 503 \\
\hline $70+0+30$ & 916 & 112 & 99 & 842 & 594 \\
\hline $90+10+0$ & 586 & 67 & 46 & 513 & 281 \\
\hline $80+20+0$ & 537 & 74 & 64 & 488 & 228 \\
\hline $70+30+0$ & 469 & 83 & 71 & 420 & 206 \\
\hline
\end{tabular}

Table 2. Monomer AA remains measures in SAP at different temperatures

\begin{tabular}{|c|l|l|l|l|l|l|}
\hline $\begin{array}{l}\text { Temperature } \\
\left({ }^{0} \mathrm{C}\right)\end{array}$ & 40 & 50 & 60 & 70 & 80 & 85 \\
\hline $\begin{array}{c}\text { Monomer } \\
\text { Residual } \\
(\mathrm{ppm})\end{array}$ & 630 & 447 & 325 & 240 & 188 & 160 \\
\hline
\end{tabular}

Table 3. Influence of $\mathrm{SiO} 2$ joins quantity to SAP coring effect and performance

\begin{tabular}{|l|l|l|l|l|l|}
\hline No & $\begin{array}{l}\text { Amount of } \\
\text { Joinning } \\
\mathrm{SiO}_{2}(\%)\end{array}$ & $\begin{array}{l}\text { Fangshi } \\
\text { Continue time } \\
(\mathrm{h})\end{array}$ & $\begin{array}{l}\text { Absorbent } \\
\text { water rate } \\
(\mathrm{g} / \mathrm{g})\end{array}$ & $\begin{array}{l}\text { Absorbent Water } \\
\text { speed } \\
(\mathrm{g} / \mathrm{s})\end{array}$ & note \\
\hline 1 & $0.2 \%$ & 0.8 & 1143 & 6 & \\
\hline 2 & $0.4 \%$ & 3 & 1157 & 8.5 & \\
\hline 3 & $0.6 \%$ & 7 & 1146 & 9 & \\
\hline 4 & $0.8 \%$ & 20 & 1150 & 9 & \\
\hline 5 & $1.0 \%$ & 22 & 1138 & 10 & \\
\hline
\end{tabular}




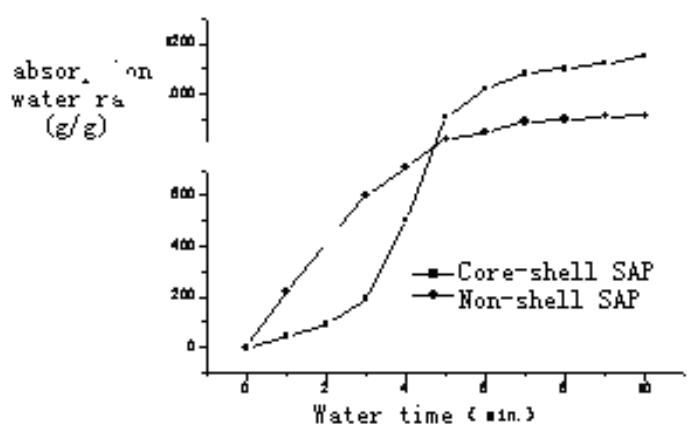

Figl Absorbing rater speed of SAP

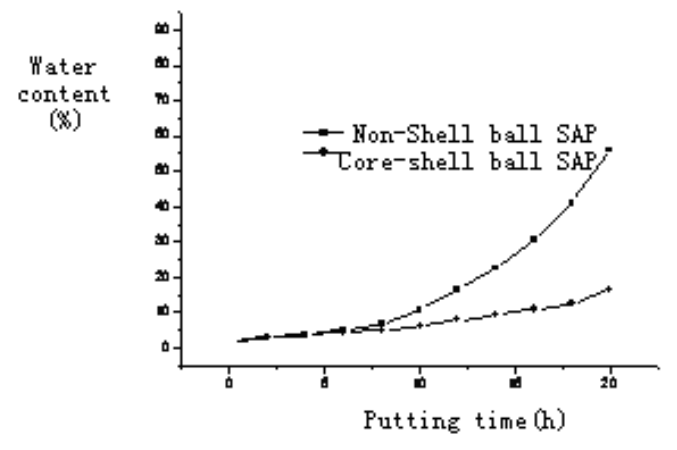

Hote: The relative humidity of $84 \%$

Fig2 Moisture absorption performance of SAP

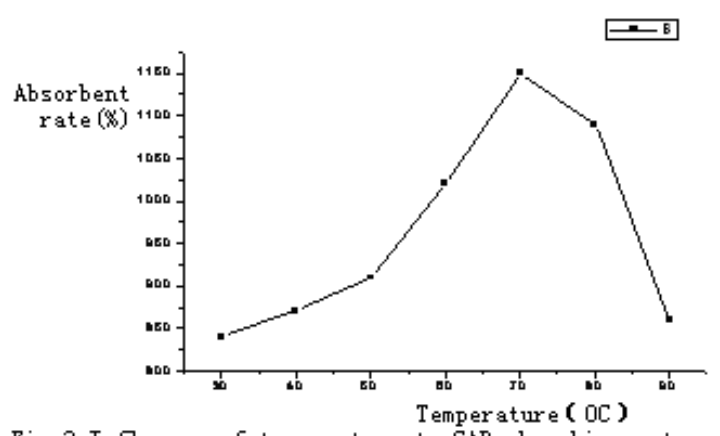

Fig 3 Influence of temperature to SAP absorbing water percentage 


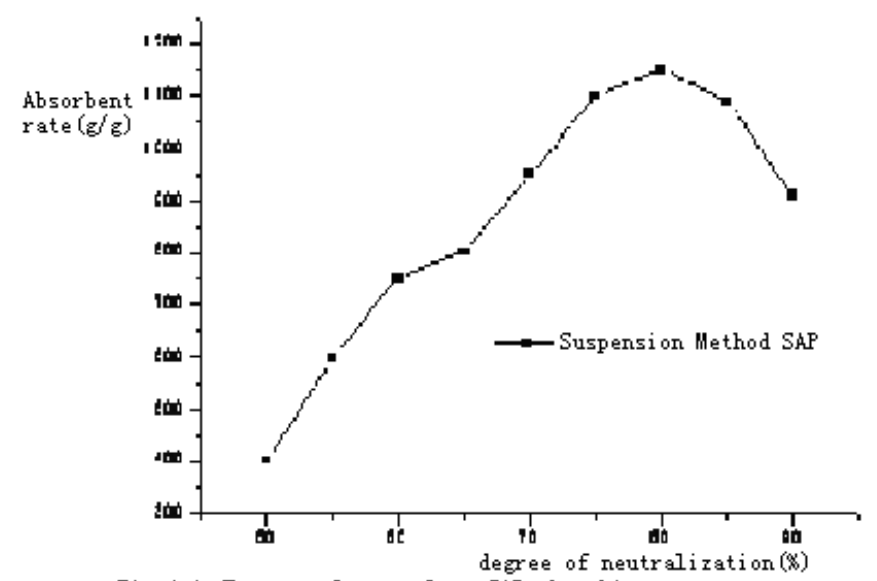

Fig 4 influence of neutral to SAP absorbing water percentage

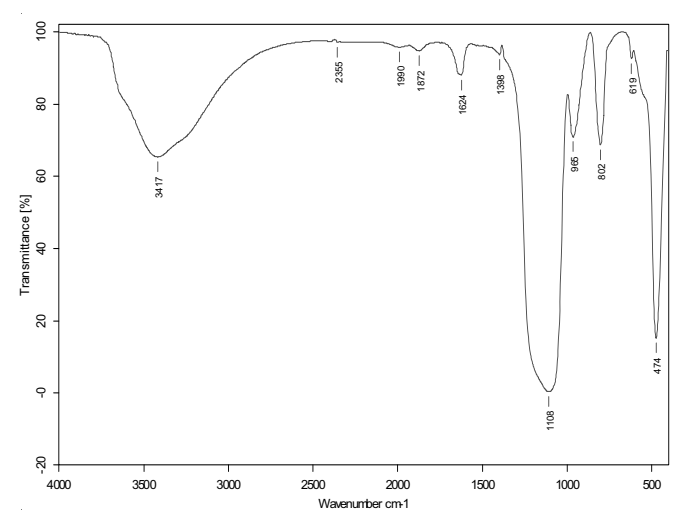

Figure 5. Infrared light spectrogram of $\mathrm{SiO} 2$

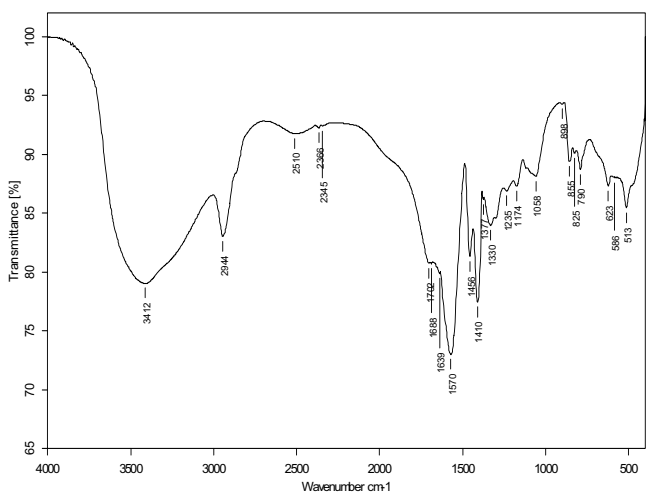

Figure 6. Infrared light spectrogram of $\mathrm{SiO} 2$ superficial stem grafting SAP 


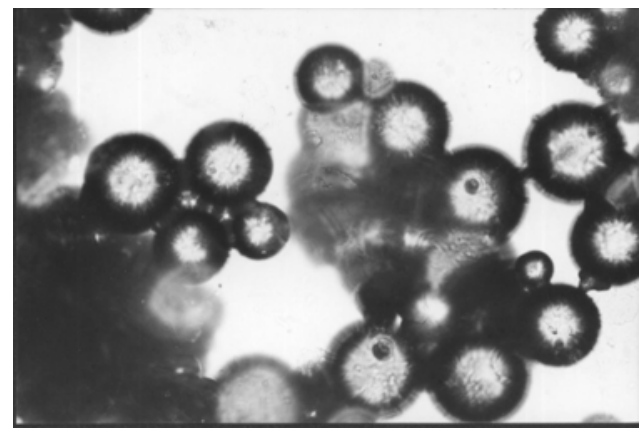

Figure 7. High power microscope chart of SAP by opposition suspension method preparation

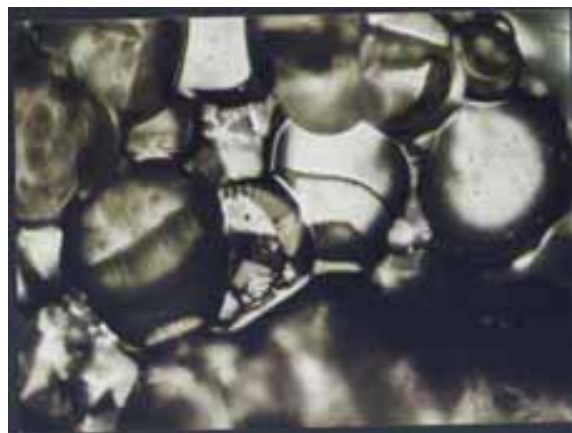

Figure 8. Chart after nuclear shell SAP absorbing water

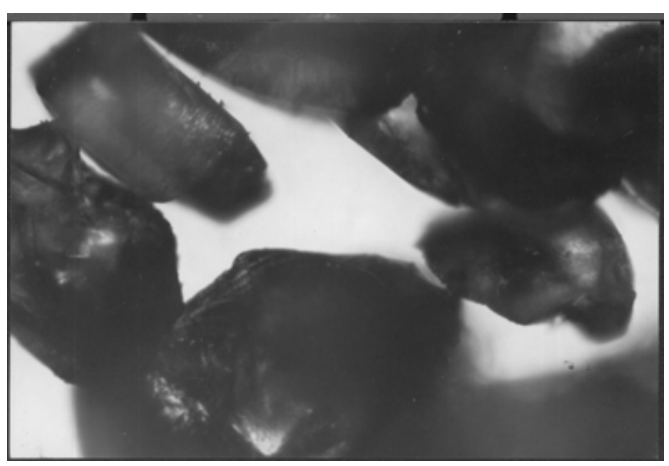

Figure 9. SAP microscope chart by solution polymerization preparation 